\title{
Päikesekuninga kontseptsiooni tekkest ja arengust Anatoolias II eelkristlikul aastatuhandel ${ }^{1}$
}

\author{
Vladimir Sazonov
}

\begin{abstract}
Teesid: Päikesekuninga kontseptsioon oli levinud muistsetes kultuurides, näiteks Peruus (inkad), Indias ja muistses Lähis-Idas juba 3. ja 2. eelkristlikul aastatuhandel. Vanas Egiptuses tekkis idee vaaraost kui Ra pojast ja päikesekuningast juba Vanas Kuningriigis 3. eelkristliku aastatuhande keskpaigaks. Kuningat kõnetasid päikesena hetiidid ja babüloonlased, samuti assüürlased juba 2. eelkristlikul aastatuhandel. Hetiitidel sai eriti populaarseks kuninglikuks tiitliks Minu Päike, mida võib tõlgendada ka majesteedina. Esimene Assüüria valitseja, kes võttis kasutusele epiteedi "kõikide inimeste päikesejumal”, oli despootlik Tukulti-Ninurta I (1244-1208). Osa teadlasi väidab. et päikesekuninga kontseptsioon tekkis Mesopotaamias ja Anatoolias Egiptuse mõjutusel. See ei tundu aga kuigi põhjendatud, sest arvatavasti puudusid Egiptusel 3. eelkristlikul aastatuhandel kontaktid Mesopotaamia ja Anatooliaga (vähemalt pole selle kohta andmeid), 2. aastatuhandel olid need juba tekkinud, aga ka siis oli Egiptuse mõju Anatooliale üsna minimaalne. Samas oli Mesopotaamia ja enne hetiitide tulekut Anatoolias elanud kohaliku hatti rahva mõju hetiidi ideoloogiale tohutu. Hulk mõisteid hetiidi kuningluses pärineb eelkõige Mesopotaamiast, samuti hattidelt. Leidub kaudseid tõendeid, et päikesekuninga idee võis tekkida juba 3. eelkristliku aastatuhande lõpus Sumeris ja Akkadis ning levida sealt tasapisi ka Anatooliasse. Samas ei saa välistada teooriat, et nii Mesopotaamias kui ka Anatoolias võis see nähtus tekkida sisemise arengu tulemusena iseseisvalt ilma suuremateta välismõjutusteta.
\end{abstract}

Märksõnad: Anatoolia, assüürlased, Egiptus, hetiidid, ideoloogia, kuninglik epiteet, Mesopotaamia, päikesekuningas,valitseja jumalikustamine

\section{Sissejuhatus}

Päikesekuninga fenomen on maailma ajaloos väga iidne nähtus, mis tekkis hiljemalt 3. eelkristlikul aastatuhandel Lähis-Idas. Ajaloos tunneme erinevatest epohhidest mitmeid päikesekuningaid - egiptuse vaaraod, hetiidi kuningad. Ei tohi unustada ka inkade valitsejaid, keda peeti elavateks jumalateks, päikese poegadeks ja päikesejumala maapealseteks kehastusteks (Kulmar 2007: 
258). Tuntuim neist oli vallutaja Ramses II (1279-1213). Mainimist väärib ka india mütoloogiline tegelane Ikškvaku, Päikesedünastia rajaja, kelle riigi pealinn oli Aidohja. Veel tuleks tuntuimatest päikesekuningatest mainida Prantsusmaa absolutistlikku valitsejat Louis XIV (1643-1715), ${ }^{2}$ kelle 72 aastat kestnud valitsemine läks ajalukku kui üks hiilgavaimaid perioode maailma ajaloos ja selle võiks kokku võtta deviisiga, mis oli Louis XIV käsul kirjutatud tema enda vapile: vires acquirit eundo [saab jõu liikumises].

Valitseja austamine päikesena ja päikese pojana on väga arhailine traditsioon. Kus ja millal tekkis esmakordselt seos, et kuningas on päike, päikese poeg? Üks selliseid kohti oli muidugi Vana Egiptus. Teine analoogiline paik oli Mesopotaamia. Kolmandaks kultusliku suhtumise sünnimaaks võiks pidada Anatooliat.

\section{Probleemi uurimisest}

Üllatav on see, et päikesekuninga kontseptsiooniga Mesopotaamias ja Anatoolias on assüürioloogias seni vähe tegeldud, v.a mõned üksikud artiklid ja uurimused. Kuid ka need on enamasti liiga spetsiifilised - pühendatud vaid teatud kitsale probleemile. Lisaks on osa neist uuringutest juba vananenud, nagu näiteks H. Th. Bosserti (Bossert 1957: 97-122) või W. Fauthi (Fauth 1979: 227-263) artikkel, samas on olemas ka märksa uuemaid uurimusi nagu näiteks Gary Beckmani artikkel (Beckman 2002: 37-43).

Paljudes uurimustes väidetakse, et arusaam valitsejast kui päikesest tekkis esmakordselt muistses Egiptuses, mis on väga tõenäoline. Just sealt olevat see levinud Anatooliasse, st hetiitidele, kes hakkasid kasutama sellist tiitlit nagu dUTU-ši ehk Minu Päike, mis akkadi keeles kõlas kui Šamšĩ ja hetiidi keeles nähtavasti kui Istanus=mis (Beckman 2002: 37). Gary Beckmani sõnul:

Although the writing is invariable, in discourse it may be applied to the first, second, or third person. By convention, Hittitologist translate this expression as "My/Your / His Majesty", respectively [Kuigi kirjapildis tiitel ei muutu, võib seda suuliselt kasutada esimeses, teises või kolmandas isikus. Traditsiooniliselt tõlgivad hetiitide uurijad seda väljendit vastavalt Minu/Sinu/Tema Majesteet] (Beckman 2002: 37).

Tiitel Minu Päike (dUTU-ši) oli kahtlemata hetiidi kuningate kõige tähtsam epiteet. ${ }^{\mathrm{d} U T U}-s ̌ i$ tekkis akkadikeelsest sõnast šamšu (samuti variantidena šanšu, šaššu), mis tõlkes tähendas päikest, päikesevalgust, päeva. Šamšu oli päikesejumala Šamaši (sum dUTU) sünonüüm (CAD 17, part I, 335). 
Ajaloolane Eduard Meyer avaldas arvamust, et hetiidi valitsejad olid võtnud selle tiitli üle egiptlaste mõjutusel (Meyer 1928: 512). Gary Beckmani sõnul on osa teadlasi tänini sellel arvamusel (Beckman 2002: 37). Siinjuures tuleb kindlasti mainida F. Corneliuse uurimust (Cornelius 1971: 343). Kõige varasemad andmed ${ }^{\mathrm{d}} \mathrm{UTU}-s ̌ i$ esinemisest hetiidi kuningate tiitlina pärinevad hetiidi kuninga Zidanta II valitsemisajast (Zidanta II leping Pilliya'ga Kizzuwatnast, 15 saj eKr keskpaik) (Beckman 2002: 37; vt ka KUB 36.108 (CTH 25) obv. 1. ${ }^{\mathrm{d} U T U}{ }^{\check{s i}}$ LUGAL.GAL ${ }^{\mathrm{m} Z i-d a-a n-y a ~ L U G A L ~ K U R ~}{ }^{\text {uru }} \mathrm{Ha}$-[at-ti]).

Gary Beckman näitab, et Mesopotaamia mõjutused hetiidi kuningavõimule olid üsnagi tugevad (Beckman 2002: 43). Samas väidab ta, et hetiidi kuningavõimu ideoloogia on paljude Mesopotaamia institutsioonide imitatsioon, kuigi Mesopotaamia ja hetiidi kuningavõimu vahel oli terve hulk tähtsaid erinevusi (Beckman 2002: 43). Kuid antud artiklis ei vaatle me võimalikke mõjutusi ja erinevusi, vaid püüame välja selgitada hetiidi valitsejate tiitli Minu Päike päritolu.

Arhailine tiitel Minu Päike (dUTU-ši) sai hetiidi valitsejate populaarseks epiteediks arvatavasti juba kuningas Hattušili I ${ }^{3}$ ajal (1650-1620 eKr), kes nimetas ennast oma hetiidi-akkadi kakskeelses tekstis päikeseks (Bossert 1957: 101-102), teda peetakse Vana Kuningriigi (1650-1500 eKr) rajajaks. Samas on kindlalt teada, et alles hetiidi kuningas Zidanta II (valitses 15. sajandi keskel eKr) kasutas epiteeti dUTU-ši (Beckman 2002: 37). Tiitli Minu Päike päritolust ei tea me eriti midagi ning see on tekitanud palju diskussioone teaduskonverentsidel ja uurimistöödes. Seoses päikesekuninga kontseptsiooniga oleks vaja vaadelda hetiidi kuningavõimu kõiki võimalikke mõjutajaid. Oleks loogiline alustada Anatoolia kohalikust rahvast, hetiitide eelkäijatest hattidest. Me teame väga vähe hatti kuningavõimu ideoloogiast, hetiidi valitsejate tiitlitest ei tea me peaaegu mitte midagi (Beckman 2002: 38). Samas on teada, et hatti religioon ja nähtavasti ideoloogia üldiselt mõjutasid hetiidi tsivilisatsiooni kujunemist tugevalt. Hetiidi monarhia ja selle institutsioonid tekkisid kohaliku hatti rahva ning sisserännanud indoeurooplaste - hetiitide, palailaste, luvilaste sümbioosi tulemusena. G. Beckman kirjutab:

Hittite monarchy as an institution combined features from the inherited Indo-European culture of the Hittite invaders with elements borrowed from indigenous Hattic civilization encountered in Anatolia [Hetiidi monarhias segunesid Hetiidi sissetungijate poolt ülevõetud indoeuroopa kultuuri jooned Anatoolias kohatud hattidest põliselanike tsivilisatsiooni sugemetega] (Beckman 2002: 38).

Epiteet Minu Päike ( ${ }^{\mathrm{d} U T U-s ̌ i}$ ) oli hetiidi kuningate seas väga populaarne hetiidi impeeriumi kokkuvarisemiseni, mis leidis aset umbkaudu 1200-1180 eKr "me- 
rerahvaste" sisserände tõttu (Bryce 2005: 333). Niisiis oli kuninglik epiteet dUTU-ši (akkadi keeles Šamšī) Hetiidi riigis kasutusel vähemalt juba 2. aastatuhande keskpaigast ${ }^{4}$ ja oli üsnagi levinud hetiidi valitsejate kirjades, diplomaatilistes tekstides, bulladel jne. Näiteks kuningas Tuthalija IV ajast on säilinud savist bulla, millel on tema pitsati jäljend, kus teda on nimetatud Minu Päikeseks:

$$
\begin{aligned}
& { }^{[N] A} K I \check{S} I B \text { dUTU-ši } \\
& \text { mTu-ut-ha-li-ia } \\
& \text { [L]UGAL.GAL-B[I] } \\
& \text { LUGAL KIŠŠSA-TI }
\end{aligned}
$$

[Minu Päikese [majesteedi], Tuthalija, suurkuninga, maailma kuninga, pitsat] (Fauth 1979: 227).

Ka rahvusvahelistes lepingutes esinevad hetiidi kuningad tiitliga Minu Päike:

1. um-ma ${ }^{\mathrm{d} U T U-s ̌ i ~}{ }^{\mathrm{m}} \check{s} u-u p-p i-l u-l i-m a$

2. LUGAL GAL LUGAL KUR ha-at-ti UR.SAG

[1. Nii räägib Minu Päike, Šuppiluliuma,

2. suurkuningas, Hatti kuningas, kangelane] (vt Aboud 1994: 48, der Vertrag RS 17.277, read 1-2, CAD 17 I: 336).

Arvatakse, et hetiidi kuningate tava nimetada ennast Päikeseks võis olla tingitud Egiptuse mõjudest. Gary Beckman kirjutab:

Furthermore, no other aspect of Hittite kingship reveals obvious Egyptian features. It therefore seems prudent to seek models for the epithet ${ }^{d} U T U^{s i}$ closer to the Hittite homeland [Pealegi ei viita ükski teine Hetiidi kuningavõimu tahk üheselt ühisjoontele Egiptusega. Seega tundub otstarbekam otsida ${ }^{d} U T U$ ši tiitlile vasteid hetiitide kodumaale lähemalt] (Beckman 2002: 38)

Kuid tuntud hetitoloogi Gary Beckmani sõnul polnud siis, kui hetiidid selle tiitli kasutusele võtsid, veel olemas otseseid kontakte Egiptusega (Beckman 2002: 37). See asjaolu välistab ka Egiptuse mõjutused hetiidi kuningavõimule sel ajal.

Üks hetiidi tekst kultuse reorganiseerimisest (KUB XLVIII 105 ja Kbo XII 53) nimetab hetiidi valitsejat mitu korda Minu Päikeseks ( ${ }^{\mathrm{d} U T U}$-ši) (Archi \& Klengel 1980: 143, rida 6’). Muuseas kasutas seda tiitlit ka hetiidi kuningas Šuppiluliuma I (1380-1340 eKr), suur vallutaja, kes purustas Mitanni riigi. Lisaks võib tähtsat kuningliku epiteeti Minu Päike ( ${ }^{\mathrm{d} U T U-s ̌ i, ~}{ }^{\mathrm{d}}$ Šamši) leida veel paljudest tekstidest, kasvõi "Hattušili III apoloogias", kus hetiidi kunin-

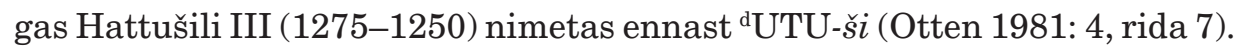




\section{Päikesekuningas hetiidi kunstis}

Hetiidi kunstis kujutati hilisemaid kuningaid (Tuthalija IV) päikesejumaluse võimutunnustega ja päikesejumalatele omases riituses. Seda võib näha kasvõi tuntud Yazilikaya kaljureljeefidel, kus on kujutatud mitmed jumalused ja hetiidi kuningas Tuthalija IV (1250-1220). Hetiidi suurkuningas Tuthalija IV pole välimuselt vähimalgi määral eristatav päikesejumala kujutisest. Ainsana aitab teda eristada asjaolu, et päikesejumalal on olemas inskriptsioon ${ }^{\mathrm{d}} \mathrm{UTU}$ AN, mida võiks tõlkida kui Taeva päikesejumal (Bossert 1957: 97). Ka on Tuthalija IV peas ümmargune müts nagu päikesejumalalgi. Üleval on tiibadega päikesekuju (Bossert 1957: 98). Pitsatil nr 63 (Güterbock 1940, I: 38-39) on kujutatud hetiidi valitsejat (oletatavasti Tuthalija IV) või jumalust, kelle pea kohal on tiibadega päike. H. G. Güterbock oletas, et tegemist on mäejumalaga (Berggott) (Güterbock 1940 I: 38-39). Et pitsatil on selgesti loetav inskriptsioon [m]Tu-uth[a]-1[i-ia], võis see pitsat kuuluda Tuthalija IV või tema järglastele (Güterbock 1940 I: 38). Samas on Yazilikajas asuvatel bareljeefidel kujutatud kuningas Tuthalija koos tiibadega päikesega (vt Klengel \& Klengel 1970, illustr 37 (suurus $74 \mathrm{~cm}$ ) ja illustr 38 (suurus $1,70 \mathrm{~m}$ ), vt ka lk 239). Illustratsioonil nr 38 on kujutatud Tuthalija IV oma kaitsejumala Šarumma embuses. Kuninga kohal üleval paremas nurgas asub kartušš kuninga nimega (Klengel \& Klengel 1970, illustr 38). Hetiidi valitsejate tiitel ${ }^{\mathrm{d} U T U}$-ši kuulus ametlikult kuningavõimu ideoloogiasse, oli selle osa (Beckman 2002: 37).

\section{Päikesekuningas Egiptuses, vaarao kui jumala Ra poeg}

Egiptuse vaaraosid peeti jumalateks vähemalt III eelkristliku aastatuhande alguses, see on ammu tõestatud fakt (Berlev 2003). Juba alates Vanast Kuningriigist (28-23 saj eKr) kuni Egiptuse tsivilisatsiooni lõpuni oli Egiptuse vaaraode kujutiste kohal tiibadega päikeseketas (Berlev 2003: 7). IV dünastia (28.-26. saj eKr) ajal, mil ehitati kõige silmapaistvamad ja suuremad Giza püramiidid (Hufu, Hafra ja Menkaura) kehtestati uus päikesereligioon ja just siis tekkis ka arusaam vaaraost kui päikesekuninga pojast (Berlev 2003: 3). Epiteet $R$ a poeg esineb esimest korda IV dünastia vaarao Džedefra pühamu kivil, kuid Sergei Stadnikovi sõnul polnud see veel tiitel vaid lisaepiteet, ning alles alates Keskmisest Kuningriigist hakati kasutama tiitlit $R a$ poeg ametlikult valitsejate nimede ees (Stadnikov 2007: 111; Stadnikov 1998: 101). Päikeseketas esines esimest korda kuningas Snofru (snfrw) abikaasa Hetpehrasi baldahhiinil (Berlev 2003: 7), ${ }^{5}$ seega juba III dünastia ajal (ca 28. saj eKr). Vene egüptoloogi Berlevi (1933-2000) sõnul olid nii vaarao kui ka päike tihedalt seotud, 
kuna mõlemad valitsesid Egiptust. Kui kuningas valitseb mõlemat-Alumist ja Ülemist Egiptust, siis Päike valitseb Ülemise ja Alumise Egiptuse taevaste üle. Ja nad pole lahutamatud, nad on nagu üks tervik (Berlev 2003: 9).

Valitsev vaarao oli "noorem jumal", "noorem päike", surnud valitseja polnud enam "noorem jumal", ja ta läks taevasse oma hauakambrisse, kus ta elas edasi nagu päike, sulades kokku oma Isa Päikesega (Berlev 2003: 14). Just V dünastiaga seostatakse Egiptuses suuri religioosseid ja ideoloogilisi muudatusi - V dünastia vaaraode ajal juurutati päikesejumala Ra üleriigiline kummardamine. Ra oli Heliopolise peajumal ja just Heliopolisest olidki pärit V dünastia vaaraod. Vaarao oli nüüd samastatud mitte ainult Horosega, keda peeti varadünastiliste kuningate patrooniks, vaid koguni Ra pojaga (IDM 1989: 159).

On teada, et Egiptuses mainiti vaaraod vahel kui [Egiptuse] kuningas on igavene päike (akkadi keeles šarru dUTU dārītu) (CAD 17 I: 336), samuti nimetati teda Ra pojaks (Montet 2000: 263) ja Päikeseks. Teadupärast valis V dünastia kolmas vaarao endale trooninimeks Neferirkara (2477-2467), mis pidi näitama vaarao erilist sidet jumal Ra'ga.

Komme ümbritseda nii trooni- kui ka sünninimi kartušiga st ovaaliga (egiptuse k šnw) on täheldatav Vanast Kuningriigist. Šnw on tuletatud verbist šnj (hõlmama, piirama). Nime paigutamine kartušši märkis arvatavasti egiptlaste käsitlust vaaraost kui päikesega hõlmatud kõiksuse isandast (Stadnikov 1998: 101). ${ }^{6}$ Näiteks ütles juba tunduvalt hiljem XXII Lüübia dünastia rajaja vaarao Šešonk (945-924 eKr) enda kohta muu hulgas Ra poolt armastatud ja AmunRe (Ra) poolt armastatud (Clauss 2001: 199).

$\mathrm{V}$ dünastia vaaraod, keda peeti Ra poegadeks, rajasid Memphise linnast lääne poole võimsaid monumentaalseid templeid, mille keskel asus mastaba ja tipus massiivne obelisk, mis pidi kehastama päikesekiirt. Need templid olid järgmised: "Ra aeg" (Userkaf), "Ra riik" (Sahura), "Ra südame kuulsus" (Niuserra), "Täiuslik Ra" (Neferra), "Ra südame koht" (Kakai) ja "Ra horisont" (Menkauhor) (Moret 2007: 176). Ei maksa unustada, et V ja VI dünastia Egiptuse valitsejad ei muutunud siiski päikesepreestriteks ja muidugi ei arenenud Egiptuse kuningavõim teokraatlikuks monarhiaks. Siiski olid Egiptuse vaaraod piiramatu võimuga valitsejad, kelle eeskujuks oli kindlasti nende isa Ra (Moret 2007: 171).

Nagu näha, pidas vaarao ennast päikeseks ja päikese pojaks juba alates vähemalt III eelkristliku aastatuhande keskpaigast. Aga kas see arusaam levis Egiptusest Anatoolia ja Mesopotaamia aladele või oli see Anatoolias ja Mesopotaamias kohalik idee?

Artikli kirjutaja eesmärk on juhtida tähelepanu asjaolule, et hetiitide puhul on kuningavõimu ideoloogiat, sh päikesekuninga kontseptsiooni teket tugevasti mõjutanud muistne Mesopotaamia traditsioon, mitte Egiptus. Oletan, 
et päikesekuninga kontseptsiooni teke Anatoolias II aastatuhandel eKr ja ka Mesopotaamias pole seotud Egiptuse mõjutustega, nagu seda mõnikord väidetakse. Esiteks. III eelkristlikul aastatuhandel peaaegu puudusid suhted Mesopotaamia ja Egiptuse vahel, need tekkisid alles III aastatuhande lõpuks. Teiseks on mõnevõrra määrav Anatoolia geograafiline lähedus Mesopotaamiaga, samuti asjaolu, et Mesopotaamia kiilkirjakultuurid (Assüüria, Babüloonia ja Mitanni) jätsid väga sügava jälje hetiidi ideoloogia, religiooni, kirjanduse ja ka terve tsivilisatsiooni arengusse. Egiptus seevastu hetiidi kultuuriruumi peaaegu ei mõjutanud ja kui mõjutaski, siis vaid kaudselt Süüria ja Palestiina linnriikide kaudu.

\section{Võimalikud Mesopotaamia mõjutused hetiidi kuningavõimule}

Nagu öeldud, olid kiilkiri, paljud religioossed pidustused, teadussaavutused ning ka peaaegu kõik hetiidi riigis kasutusel olevad kuninglikud tiitlid ja epiteedid nagu LUGAL (kuningas), LUGAL KIŠ (maailma kuningas), narām (akkadi k 'armastatu', 'lemmik'), Šamši (akkadi k 'Minu Päike') laenatud mesopotaamlastelt. ${ }^{7}$ Mesopotaamia kirjandus, religioon ja ideoloogia mõjutasid hetiite kas otse või hurriitide kaudu, kes elasid Anatoolias, Süürias ja ka Põhja-Mesopotaamias. Lisaks oli hetiidi kuningavõimu ideoloogia tugevasti mõjutatud Mesopotaamia (Babüloonia, Assüüria, Mitanni) ideoloogiast ja usunditest. 8 Terve hulk sõnu sugenes hetiidi keelde laensõnadena sumeri ja akkadi keelest, näiteks kuningavõimuga seotud mõisted palee (sumeri k É.GAL), valitseja (sumeri k EN, akkadi k bēlu(m)), kuningas (sumeri k LUGAL) (Sazonov 2009: 51).

Sumerogramm LUGAL tähendab kuningat, selle akkadikeelne vaste on šarru $(m)$. LUGAL oli võetud kasutusele juba varadünastilises Sumeris vähemalt 28.-27. sajandil eKr. Esialgselt tähendas LUGAL suurt inimest (sumeri k lú - inimene, gal - suur), meest tähtsal positsioonil. Esmalt tähistati selle mõistega peamiselt sõjapealikke. Varadünastilisel ajastul (2800-2334 eKr) hakati nii nimetama ka linnriikide valitsejaid, näiteks Kiši I dünastia või Ur I dünastia kuningaid.

Silmas tuleb pidada, et hetiidi kuningaideoloogial, sh tiitlitel, oli märgatav omapära, muidugi kasutati ka täiesti uusi Anatoolia päritolu tiitleid ja epiteete nagu haššu- (vt nt Haas 1994: 188), tabarna (vt Puhvel 2002: 131; Gonnet 1987), tavananna (Bin-Nun 1975), tuhkanti- (Gurney 1984) jne, mis olid algselt kas hetiidi (indoeuroopa) või hoopis kohaliku hatti päritolu.

Akkadi kuningaid Sargon I (2334-2279 eKr) ja Narām-Su'eni (2254-2218 eKr) ülistati Mesopotaamia ja hetiidi kirjanduses. Sargon I sai ideaalvalitseja prototüübiks ka hetiidi kuningate silmis. Akkadikeelne legend Šar tamhari 
(akkadi k 'Lahingu kuningas'), mis käsitles Sargon I sõjaretke Purušhandasse (asus Anatoolias), samuti teised legendid Sargon I ja Narām-Su'enist olid populaarsed ka hetiitide seas (vt Haas 2006: 67-76; Westenholz 1997: 102-139). Selliseid näiteid võiks tuua veelgi.

Peatuksime vaid tiitlitel ja epiteetidel, mis on seotud päikesekuninga kontseptsiooniga Anatoolias ja Mesopotaamias. Tuntuim hetiidi kuninglik epiteet on muidugi Minu Päike ( ${ }^{\mathrm{d} U T U-s ̌ i), ~ m i d a ~ v a h e l ~ t o ̃ l g i t a k s e ~ k a ~ m a j e s t e e d i n a . ~ T i i-~}$ tel tekkis akkadikeelsest sõnast šamšu (variantidena ka šanšu, šaššu), mis tõlkes tähendas päikest, päikesevalgust ja ka päeva. Mõiste šamšu oli ka Babüloonia ja Assüüria päikesejumala Šamaši (sum d UTU) sünonüüm (CAD 17 I: 335). Akkadi-keelne dUTU-ši (Minu Päike) oli Hetiidi riigis üsnagi levinud, vahel isegi Egiptuse vaaraode tähistusena. Eriti tähtis on asjaolu, et just Egiptuse vaaraod olid võtnud kasutusele akkadikeelsed epiteedid, sh dUTUši , mitte vastupidi.

Akkadi keel oli II eelkristlikul aastatuhandel muutunud rahvusvaheliseks keeleks ja isegi Tell el-Amarna arhiivis (Moran 1992, xviii-xix) Egiptuses oli egiptlastest kirjutajaid, kes kirjutasid akkadi kiilkirjas ning panid kirja akkadi legende ja eeposi. Ka Egiptuse vaaraode kirjavahetus Hetiidi, Assüüria, Babüloonia, Süüria ja Palestiina valitsejatega toimus akkadi keeles.

Juba esimesed hetitoloogid Ferdinand Sommer ja Helmuth Theodor Bossert (1957) arvasid, et hetiidi kuninganimetuse Minu Päike tekkimisel pole mingit pistmist Egiptuse mõjutustega. ${ }^{9}$ Pigem oli see Mesopotaamia mõju.

Huvitav oleks vaadata, kas samal ajal on kasutatud ka sarnaseid epiteete naaberriikides - Assüürias ja Babüloonias.

Kesk-Assüüria riigist on umbes samast ajast teada, et Assüüria kuningas Tukultī-Ninurta I (1244-1206) nimetas ennast kõikide inimeste päikesejumalaks - ${ }^{d} \check{s} a m$-šu kíššat nišêmeš (Weidner 1970: 11; vt ka Sazonov 2008a: 11-12). Seega on täiesti võimalik, et kuningas pretendeeris jumalikule staatusele, päikesejumala staatusele. Tiitel võis pärineda amoriitidelt, kes hõivasid Mesopotaamia II eelkristliku aastatuhande alguses (ca 20.-19. saj eKr), st umbes IsinLarsa ajal (20.-18. saj eKr). On teada, et üks tuntuimatest amoriitidest, kes vallutas terve Põhja-Mesopotaamia ja keda peetakse Vana-Assüüria kuningaks, kandis nime Šamš̄̄-Adad I (1813-1781), mis tõlkes tähendas Jumal Adad on Minu Päike. ${ }^{10}$ Larsa viimane kuningas Rim-Sin (1822-1763 eKr) esines kui lugal-kala-ga ${ }^{d} U T U$ kala-ma-na [võimas kuningas, oma maa päikesejumal] (Beckman 2002: 39). Tegelikult on meil andmeid juba III aastatuhandest selle kohta, et valitseja pretendeeris päikese staatusele, näiteks Nagari (tänapäeva Tell Brak) valitsejat, kes kandis huriidi päritolu nime Talpuš-atili, nimetati ${ }^{\mathrm{d}} \mathrm{UTU}$ māti (Maa päikesejumal) (Beckman 2002: 39, Matthews \& Eidem 1993: 202; Buccellati \& Kelly-Buccellati 2002: 20). Seega on võimalik, et päikesekuninga 
idee võis tulla Anatooliasse koguni hurriitidelt, kes olid hetiitide lähimad naabrid väga pikka aega.

Tiitel ${ }^{d} U T U^{s i}$ muutus eriti populaarseks hetiidi kuningatel. Ka Babüloonias oli see levinud, näiteks amoriidi päritolu kuninga Hammurapi (1792-1750) poja nimi oli Samsuiluna. Ta valitses Babülooniat aastail 1749-1712 eKr. Samsuiluna nimi tõlkes amoriidi keelest tähendab Meie Jumal on Päike. Mõnikord nimetasid Babüloonia kuningad ennast järgnevalt: Võimas kuningas, Babüloni päike - šarru dannu ša-[am-šu] Bābilim (CAD 17 I: 337). Hammurapi seaduste proloogis väidab Hammurapi, et ta on Šamaši kombel tõusmas mustapealiste kohale maa üle valguse heitmiseks (Amar Annuse tõlge, vt Annus \& Kolk \& Päll \& Puhvel 2001: 89; kīma Šamaš ana şalmāt qaqqadim waşê=ma mātim nuwurrim; transliteratsioon Roth 1997: 76-77).

Samas on teada, et 18. sajandil Mari linnas valitsenud kuningat Zimrilimi on mitmes talle adresseeritud kirjas nimetatud kui kakkabī (Minu Täht), kusjuures vähemalt üks kord on teda nimetatud ${ }^{\mathrm{d}} U T U^{s i}$ (Minu Päike) (Beckman 2002: 38).

Assüroloog Stephan M. Maul loetleb oma artiklis Kesk- ja Uus-Assüüria

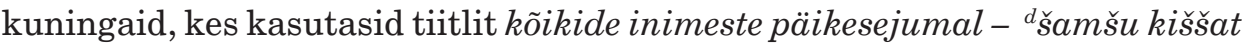
nišē: Tukultī-Ninurta I, Adad-nīrāri II, Tukultī-Ninurta II, Aššurnasirpal II, Salmanassar III ja Assarhaddon (Maul 1999: 206).

Nagu näeme, oli päikesekuningas II eelkristlikul aastatuhandel muutunud populaarseks nii Mesopotaamias, kui ka Anatoolias ja muidugi eriti Egiptuses. Aga vaatame korraks, mida näitavad meile III eelkristlikust aastatuhandest pärinevaid allikad Mesopotaamiast. Äkki leidub ka seal midagi huvitavat?

\section{Šamaši roll Akkadi ajastul}

Päikesejumalat sumeri Utut ehk akkadi Šamašit hakati kuninglikes raidkirjades mainima juba Akkadi ajal (2334-2154 eKr). Sumeri päikesejumal Utu oli sumerlastel üks tähtsaimaid jumalaid ning Sipparis ja Larsas asusid tema peamised pühamud. ${ }^{11}$ Varajase sumeri kuningavõimu ideoloogias Utul olulist rolli ei olnud. Alles hiljem, eriti Hammurapi (1792-1750 eKr) ajal hakkas Šamaši roll kasvama ja seda seostatakse amoriitidega, sest just neil oli tugev Šamaši kultus. Amoriidid, kes Ur III ajastu (2112-2004 eKr) lõpus ja Isin-Larsa ajal (2004-1763 eKr) hõivasid Sumeri alad, tõid endaga kaasa ka tugeva Šamaši kultuse.

Uurides Akkadi ajastu (2334-2154 eKr) tekste, tulin järeldusele, et Šamaši roll hakkas tugevnema juba Akkadi riigi rajaja Sargon I (2334-2779 eKr) ja tema järglaste ajal, st umbes 300 aastat enne amoriitide sissetungi Sumeri 
aladele. Siiski polnud Sargon I ning tema järglased Rimuš, Maništušu ja NarāmSu'en sumerlased, vaid semiidid, nagu amoriididki. Amoriidid on lääne-semiidi, akkadlased aga ida-semiidi hõimud. Muidugi hakkas päikesejumala roll vaikselt kasvama just Akkadi ajastul, ja see on seotud semiitidega, kellele oli üldse omane tugev päikesekultus. Ka egiptlastel, kes olid hamiidid, st semiitide sugulased, etendas päikesejumal riiklikus ideoloogias ja religioonis tohutult suurt rolli.

Sargon I ja tema järglased Akkadi troonil, kuningad Rimuš ja Maništušu tõid igapäevaselt rikkalike ohvreid päikesejumala Šamaši altarile (seda näitab meile näiteks tekst Rīmuš 7 (FAOS 7: 73)). Kuningas Maništušu lisas ühe oma raidkirja lõppu, kus ta kirjeldas Alumise Mere (Pärsia lahe piirkonnas) linnade vallutamist, vandevormeli, kus mainis Šamaši ja Ištarit, kes pidid karistama seda, kes oleks selle raidkirja hävitanud või purustanud (FAOS 7: 75-77).

Kuulsa Maništušu dokumendi (erialakirjanduses The Cruciform Monument, nimetus tuleneb sellest, et monument, millel tekst asub, on ristikujuline) tekst algab kuninga nime mainimisega, tema genealoogia ja tiitlitega (Gelb 1949: 346). Tegemist on juriidilise dokumendi ehk aktiga, mis andis Sippari linnas vabadusi ja õigusi päikesejumala Šamaši ja jumalanna Aija preestrinnadele. Seoses Šamašile kuuluva E-Babbari templi ehitustöödega Sipparis eraldas kuningas Maništušu templile suuri maa-alasid, kus asus rohkem kui 10 asulat. Templile kingitud maa oli vabastatud kõikidest maksudest, lisaks oli veel 80 ha maad eraldatud jumalanna Aija preestrinnade elamuks. Samuti nõudis kuningas, et riiklikest sissetulekutest läheksid rikkalikud ohvriannid jumal Šamaši templi hüvanguks ning määras nende ohverduste suuruse. Ka kinkis Maništušu päikesejumala templile palju kalleid riideid kujude tarvis ning vähemalt 30 kilogrammi kulda ja 60 kilogrammi hõbedat (Djakonov 1959: 230_ 231.)

Sellest järeldub, et Šamaši roll oli tunduvalt kasvanud, nagu ka jumalanna Ištari oma, keda peeti Akkadi dünastia patrooniks. Kui uurida kuningas Maništušu raidkirju, ilmneb, et kõige rohkem ohverdusi tegi Maništušu just Šamaši ja sumeri peajumala Enlili auks. Neile toodi ohvreid peaaegu võrdselt. See pole muidugi juhuslik. Võrreldes varasemate Sumeri valitsejate raidkirjadega, kus päikesejumalat ei mainitagi, toimub siin lausa kardinaalne pööre. Šamašit austas väga ka Maništušu poeg Narām-Su'en (2254-2218 eKr), kelle ajal saavutas Akkadi impeerium oma võimsuse tipu ja keda hakati esimesena Mesopotaamia valitsejatest jumalikustama. Meieni on jõudnud üks äärmiselt huvitav akkadikeelne raidkiri vasest tehtud nn Bassetki ${ }^{12}$ kujul. ${ }^{13}$ Raidkiri jutustab sellest, kuidas Narām-Su'en oli valitud jumalaks ning talle ehitati tempel Agade linnas, mis oli kogu Akkadi riigi pealinn (Edzard 1989: 104). Tõlke fragment (1.-56.) räägib sellest järgnevalt: 
Narām-Su'en, Akkadi võimas kuningas. Kui (kõik) neli maailmakaart tõusid koos tema vastu üles, armastuses, millega teda armastas Inanna (Ištar), võitis ta üheksas lahingus ühe aastaga kuningaid ja vangistas need, kes astusid tema vastu välja. Selle eest, et ta raskel (ajal) kinnitas oma linna võimsuse aluse, palusid tema linna elanikud Inannalt Eannas, Enlililt Nippuris, Daganilt Tuttulis, Ninhursağilt Kešis, Enkilt Eridus, Su'enilt Uris, Utult (Šamašilt) Larsas, Nergalilt Kutas nende linna, Agade linna jumalaks, ja ehitasid Agade linna keskele talle templi. ${ }^{14}$

Sumeri päikesejumalat Utut (akkadi Šamaš) on mainitud tähtsamate jumalate seas, kes valisid Narām-Su'eni jumalaks. See tähendab seda, et ka Utu (Šamaši) tunnustust oli vaja selleks et Narām-Su'en saaks kuningaks. Seega kuulus päikesejumal Šamaš Sumeri ja Akkadi kaheksa tähtsaima jumaluse hulka.

Kuid üheski Varadünastilise ajastu (2800-2334 eKr) ja isegi Akkadi ajastu (2334-2155 eKr) tekstis pole valitsejat kunagi otseselt seostatud päikesega, nimetatud päikeseks või kasvõi päikese pojaks. Olukord hakkas muutuma Ur III dünastia (2112-2004 eKr) ajal.

\section{Päikesekuninga kontseptsiooni võimalikud juured viivad}

\section{Sumerisse?}

Esimene huvitav viide selle kohta, et Sumeri valitseja võis olla seotud päikesega, on seotud Uruki IV dünastia kuninga Utuhengaliga, kes valitses 22. sajandi eKr lõpus, purustas sõjas gutilasi ja vabastas Sumeri nende ülemvõimust. Tema nimi tähendab sumeri keeles Jumal Utu on (minu) küllus /vägi. Pärast Utuhengali surma arvatavasti 2109. aastal eKr, viis järgmine valitseja Ur-Namma (2112-2094 eKr) pealinna Urukist Uri linna ja rajas võimsa despootliku Uus-Sumeri kuningriigi, mis sai tuntuks kui Ur III dünastia (2112$2004 \mathrm{eKr}$ ). Ur III dünastia ajal tekkis arusaam, et kuningas on jumal, jumalikustamine muutus pärilikuks ja kuningaid peeti päikesejumala Utu poegadeks. ${ }^{15}$ Siin peab silmas pidama asjaolu, et Ur III ajal ja hiljem Isin-Larsa ajal tavatsesid kuningad nimetada ennast erinevate jumaluste poegadeks. Eriti populaarne oli tituleerida ennast sumeri peajumala Enlili pojaks ja pretendeerida jumal Ninurta staatusele, kes oli Enlili poeg (vt nt Isini kuninga LipitEštari hümne, kus teda on nimetatud Enlili pojaks: 1.) Lipit-Eštar D, rida 39. [d]li-pi2-it-eš4-tar2 nun za-a-še3 ĝal2-la dumu den-lil2-la2-ke4 (ETCSL c. 2.5.5.4); 2.) Lipit-Eštar $H$, rida 6. / dli \-pi2-/it \-eš4-tar2 dumu d/en \-[lil2]-la2-ra (ETCSL c. 5.5.8)). Ühes hümnis (Šulgi A) on kuningas Šulgit nimetatud Ninsumuni pojaks: dumu $\mathrm{u}_{3}$-tud-da ${ }^{\mathrm{d}}$ nin-sumun ${ }_{2}$-kam-me-en [Mina olen laps, sünnitatud 
Ninsumunimi poolt] (ETCSL c.2.4.2.01, rida 7). Samas hümnis nimetatakse teda lisaks ka: piriĝ $\mathrm{ka} \mathrm{du}_{8}$-a ${ }^{\mathrm{d}} \mathrm{utu}-\mathrm{u}_{3}$-me-en [Mina olen (jumala) Utu möirgav lõvi] (ETCSL c.2.4.2.01, rida 14). Niisiis hakkas päikesejumal Utu etendama Ur III ajal võib olla isegi suuremat rolli kui Akkadi ajal. Ur III ajal üleskirjutatud kirjanduslikes tekstides mainitakse Utut suhteliselt tihti. Kasvõi sumerikeelses eepilises laulus "Gilgameš ja Akka”. Kui legendi kohaselt Kiši kuningas Akka sai Uruki linna seinte all lüüa, siis vastas ta Gilgamešile järgnevalt:

[Akka:] "Jumalad ehitasid Uruki, suure müüri, mis ulatub pilvedeni, Ani rajatud võimsa elupaiga. 110. Sina oled selle juht, kuningas, kangelane, vägilane, Ani armastatud vürst!"

[Gilgameš:] "Utu ees ma tagastan sulle su võimu!"

Akkale tasuks Kiši valitsemine tagasi anti.

Gilgameš, Kulaba isand,

115. sinu kiitus on meeldiv! (Sazonov\&Veede 2005: 53).

Ur III tuntuim valitseja oli Ur-Namma poeg Šulgi (2093-2046 eKr), kes oli jumalikustatud ja kelle ajast on teada, et üks tema alamatest kandis nime ${ }^{d} \check{S} u l$-[gi]-d ${ }^{d} \mathrm{UTU}^{\text {ši }}$ (Di Vito 1993: 169). Nimevormist ${ }^{d} \check{S} u l$-[gi]- ${ }^{d} \mathrm{UTU}^{\text {ši }}$ [(Jumalik) Šulgi on Minu Päike] võib järeldada, et Uus-Sumeri kuningas Šulgi pretendeeris mitte ainult jumalikule staatusele oma riigis, vaid minu arvates koguni päikesekuninga staatusele. Siiski peab märkima, et sumerlastel polnud kunagi tugevat päikesejumalakultust nagu oli semiitidel, ning pigem võis see tuleneda lääne-semiidi päritolu amoriitide mõjust, kes 22. ja 21. eelkristlikul sajandil hakkasid ilmuma ka Lõuna-Mesopotaamia aladele. Just amoriitidele meeldisid sellised nimed. Šamšī-Adad I (1813-1781), kes rajas võimsa Põhja-Mesopotaamia suurriigi, mille keskusteks said Aššur ja Ekallatum, peetakse vahel Vana-Assüüria kuningaks, kuigi ta polnud assüürlane, vaid hoopis amoriit. Nimi Šamšî-Adad kirjutati kiilkirjas ${ }^{d} U T U^{s i}$-adad, mis tähendas "Minu Päike on Adad" (vt nt RIMA 1, Šamši-Adad I A. 0.39.2003). Siiski esineb jumal Šamaš (sum Utu) teofoorse elemendina isikunimedes juba Akkadi ajastul (2334-2154)

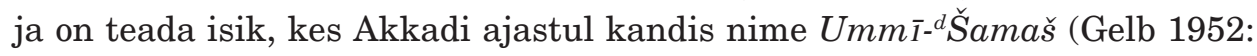
225).

Raske on öelda, kas Šulgit võib üldse vaadelda päikesekuningana nagu hilisemaid hetiidi valitsejaid. Arvatavasti mitte. Samas esineb Šulgi Sumeri päikesejumala Utu pojana, mida ei teinud ükski valitseja enne teda. Isegi jumalikustatud akkadi kuningad Narām-Su'en ja tema poeg Šarkallišarrī ei nimetanud ennast kunagi Utu pojaks või Minu Päikeseks. 
Umbkaudu Ur III ajal pandi kirja tuntud propagandistlik teos Sumeri kuningate nimekiri, mis kajastas Ur III ideoloogilist tausta ja kus olid mainitud kõik Sumeri kuningad, kes olevat valitsenud Sumeris enne ja pärast veeuputust. ${ }^{16}$ Sumeri kuningate nimekirja kohaselt algaski legendaarse varadünastilise Uruki linna valitseja Gilgameši (elas ca $2700 \mathrm{eKr}$ ) genealoogia päikesejumalast Utust. ${ }^{17}$

Kui uskuda hilisemat Ur III aja pärimust, pärinesid ka kõik teised legendaarsed Uruki I dünastia kuningad (Meškiağašer, Enmerkar, Lugalbanda (valitsenud 29.-26. saj eKr)), kes valitsesid Urukis vahetult enne Gilgameši, päikesejumalast Utust. Sumeri kuningate nimekirjas leiame koha, mida võib pidada ka selle asjaolu tõestuseks (read 96-97): meš ${ }_{3}-$-ki-ağ $_{2}$-ga-še-er dumu dutu en-am ${ }_{3}$ [Meškiağašer, (päikesejumala) Utu poeg] (ETCSL c 2.1.1, 96-97). Ka teist Uruki legendaarset kuningat Enmerkari (Lugalbanda isa) on nimetatud Utu pojaks (en-me-er-kar ${ }_{2}$ dumu ${ }^{\mathrm{d} u t u}$-ra), näiteks eeposes Lugalbanda mägede koopas (ETCSL c.1.8.2.1, rida 19).

20. sajandil eKr rajasid amoriidid Larsa riigi, mis hiljem Rim-Sini ajal (1822$1762 \mathrm{eKr}$ ) saavutas oma võimsuse tipu, isegi Isin, Nippur, Ur ja teised linnriigid (v.a Babülon, Ešnunna ja veel mõned) sattusid Larsa kontrolli alla. Larsa muistne Lõuna-Mesopotaamia linn - oli iidne päikesejumala Utu keskus, selle peapatroon oli muidugi päikesejumal Utu (akkadi Šamaš). Larsa asus strateegiliselt tähtsas kohas, kus kõige suurem kanal Iturungal suubus Eufrati jõkke. See andiski Larsa valitsejatele võimaluse alustada edukaid vallutusi, sest see, kes kontrollis niisutussüsteemi, kontrollis sisuliselt ka terve piirkonna majandust. Hiljem kui Hammurapi vallutas Larsa umbkaudu aastail 1763$1762 \mathrm{eKr}$, väitis ta, et Šamaš isiklikult aitas tal linna allutada. Hammurapi titulatuuris on kirjutatud, et ta andis Utu külluse, andestas Larsale ja renoveeris E-Babbari templi jumala Šamaši jaoks, kes oli tema liitlane (Djakonov 1990: 31-32.). Hammurapi ajal kasvas Šamaši roll tohutult. Muidugi suurenes ka Baabüloni linna peajumala Marduki tähtsus, saavutades üleriigilise staatuse (Marduki ja Hammurapi kohta vt Annus 2001: 9-19). Kuigi Enlil säilitas veel peajumala staatuse, oli Marduk hakanud teda juba välja tõrjuma. Ka Šamaš oli nüüd umbes sama tähtis kui Marduk. Seda näitavad Hammurapi-aegsed inskriptsioonid ${ }^{18}$ ja Hammurapi koodeksi $(\mathrm{CH})$ proloog, kust me loeme:

Sel ajal Hammurapi, vaga vürst, jumalatekartlik, õiguse nähtavustaja maal, kaotamaks kurja ja halba, et tugev ei kahjustaks nõrka, Šamaši kombel tõusmaks mustapealiste kohale

Maa üle valguse heitmiseks, Anu ja Enlil kutsusid mind

Minu nimega, inimeste hüveoluks

(Amar Annuse tõlge, vt MSA 2001: 89). 
Kaalutlemise kuningas, Šamaš kuulekas, võimas Sippari juurte kinnitaja, Ajja templi rohelisega riietaja, Ebabbari taevasarnase elupaiga kuulsakstegija. Sõjamees, kangelane, Larsale halastav, Ebbabbarit Šamašile, oma abile, uuendav (Amar Annuse tõlge, vt MSA 2001: 90).

\section{Järeldused}

II eelkristlikul aastatuhandel (alates ca $1650 \mathrm{eKr}$ ) tekkis ja arenes Anatoolias Hetiidi impeeriumis välja päikesekuninga kontseptsioon, kuigi see polnud kunagi nii tugev nagu Egiptuses. See kontseptsioon arenes oma lõplikus vormis välja alles kuningas Tuthalija IV (1250-1220 eKr) valitsemisajaks. Hetiidi kuningaid nimetati päikeseks ja Minu Päikeseks nii kirjavahetuses kui ka ametlikes tekstides. Minu Päike muutus nii populaarseks ja levinud epiteediks, et seda võib interpreteerida ka kui tiitlit majesteet.

Hetiidi kuningavõimu tähtsamaks patrooniks sai Arinna linna päikesejumalanna, ${ }^{19}$ keda vahel vaadeldi ka hetiidi peajumalusena, samas oli ka päikesejumala dUTU roll riigis väga suur. Sumerikeelne mõiste ${ }^{d} U T U$ (päikesejumal) pärines Mesopotaamia kultuuriruumist III eelkristliku aastatuhande algusest. Hetiidi valitsejad läksid kujutluste kohaselt surres taevasse, saades jumalateks nagu Egiptuse vaaraodki, sama toimus ka Sumeri kuninga Šulgiga (2093-2046 eKr), tuntuima Uus-Sumeri suurriigi valitsejaga. Võrdluseks Šulgi isa Ur-Namma (2112-2094 eKr), kes erinevalt oma pojast polnud jumalikustatud ja oli lihtne surelik, läks allilma (Jemeljanov 2003: 87; Ur-Namma surma kohta vt The death of Ur-Namma (Ur-Namma A), c.2.4.1.1).

Hetiidi valitsejaid, vähemalt ühte - Tuthalija IV, kujutati päikesejumala atribuutikaga. Muidugi pole välistatud kaudsed Egiptuse mõjutused, kuid isegi kui neid oli, pidid need olema minimaalsed. Palju tõenäolisemalt oli tegemist tugevate Mesopotaamia kultuuriruumi mõjutustega. On teada, et Mesopotaamia tsivilisatsioon mõjutas väga tugevasti hetiite nii kultuuri, arhitektuuri, kirjanduse, usundi, kiilkirja kui ka ideoloogia valdkonnas. Kesk-Assüüria kuningas Tukulti-Ninurta I kandis tiitlit kõikide inimeste päikesejumal, mis võis tuleneda amoriitide (lääne-semiidi hõimud) või koguni Ur III mõjust.

Antud probleem vajab põhjalikku süvenemist. Paljud asjad, mis on seotud päikesekuninga kontseptsiooni tekke ja levikuga Lähis-Idas, on esialgu segased ja hüpoteetilised. Samas pole siiski välistatud asjaolu, et päikesekuninga fenomen võis tekkida Anatoolias koguni iseseisvalt, ilma välismõjutusteta. 


\section{Kommentaarid}

1 Käesolev artikkel on välja kasvanud 4. märtsil 2008. aastal Eesti Akadeemilise Usundiloo Seltsi ettekandeõhtul peetud ettekandest. Artikkel on kirjutatud Eesti Teadusfondi grantide ETF6625 ja ETF6685 toetusel. Tänan kolleege dots Mait Kõivu, prof Thomas R. Kämmereri ja Sergei Stadnikovi, kes tegid artikli tarbeks kriitilisi märkusi ja andsid kasulike soovitusi. Samuti olen tänulik korrektuuri eest Sirje Kuppule.

${ }^{2}$ Kuigi Louis XIV epiteedil polnud religioosset tagapõhja ja see oli pigem absolutistliku ajastu kulmineerimist väljendav epiteet, kuninga isikukultuse tipp.

${ }^{3}$ Hattušili I puhul ei saa olla kindel epiteedi Minu Päike kasutamises: It appearance in the Annals of Hattušili I (CTH 4) must be disregarded here since the text in question is known only in copies from the Empire period [Selle esinemist Hattušili I annaalides $(C T H 4)$ ei saa siinkohal arvestada, kuna mainitud tekst on teada vaid Suure Kuningriigi perioodist] Vt Beckman 2002: 37.

${ }^{4}$ Wie allgemein bekannt, wurden die hethitischen Grosskönige im 2. Jahrtausend "Meine Sonne" angeredet. Darauf ist der Brauch zurückzuführen, dass der Großkönig selbst als "Meine Sonne" zu bezeichnen begann [Nagu on üldteada, nimetati hetiidi kuningaid 2 aastatuhandel Minu Päike. Seega tuli see väljend taas kasutusele ja kuningad hakkasid seda väljendit kasutama enesekohaselt] (Bossert 1957: 97).

5 Vt ka Moret 2007, kelle väitel vaarao Hafra (Chefren) (2520-2490) lisas kuninga nimele kirjutatud kartušši kaks epiteeti: neter $\hat{a} a$ ehk suur jumal, mis tähendas $R a$ ja sa Râ ehk siis Ra poeg. Alexandre Moret' sõnul jäi vaarao endiselt Horose kehastuseks Isise pojana, kuid samas sai temast ka Ra poeg ja ühtlasi Ra kehastus (Moret 2007: 165).

6 Vt ka Moret 2007: 164-165: Примерно в то же время, в начале III династии, возникает практика написания царя или иногда всех его ритуальных титулов овальной рамке на плоском основании, которую мы называем картушем. Для египтян этот овал олицетворял эллиптический ход Солнца вокруг мира и очерчивал границы царства, освещаемого солнцем, - «всё, что освещает диск (shenen) Атона [Umbes samal ajal, 3. dünastia alguses tekib tava kirjutada tsaar, aga mõnikord kõik ta rituaalsed tiitlid ovaalses raamistuses lamedale pinnale, mida me kutsume kartušiks. Egiptlaste silmis kujutas see ovaal Päikese elliptilist ringi ümber maakera ja kehastas kuningriigi piire, mida valgustab päike - kõike mida valgustab Atoni ketas (shenen)].

${ }^{7}$ Ei tohi muidugi unustada fakti, et hetiite mõjutasid tugevasti ka hattid, rahvas, kes elas Anatoolias veel enne hetiitide tulekut III eelkristlikul aastatuhandel.

8 Märgatav on ka sumeri mõju, mis tuli Babüloonia, Assüüria ja hurriitide kaudu.

${ }^{9}$ Mit Sommer bin ich der Meinung, dass der gelegentlich behauptete ägyptische Einfluss bei der Entstehung dieser hethitischen Königsbezeichnung keine Rolle spielte. Eher wird man daran erinnern dürfen, dass Grosskönige oft im Gewande und den Insignien des Sonnesgottes ausgestatt in der Öffentlichkeit ershienen [Nagu Sommer, olen ka mina arvamusel, et paiguti väidetav egiptuse mõju ei mängi selle hetiidi kuninganimetuse tekke juures mingit rolli. Pigem tasub meenutada, et suurkuningad ilmusid tihti avalikkuse ette päikesejumala rõivaste ja atribuutidega] (Bossert 1957: 97).

10 "Minu Päike" esineb Mesopotaamias veel mitmes isikunimes nagu Aššur-šamš+ (Aššur on Minu Päike) jne (vt Beckman 2002: 39). 
${ }^{11}$ Utu tähtsust varadünastilises Sumeris tähistavad sumerikeelsed müüdid 26.-25. saj eKr, leitud Ebla linnast (asub Süürias), kus Utu oli üks peategelasi.

${ }^{12}$ Bassetki küla asub Iraagis Mosulist Zāhō’sse viiva tee ääres.

13 Suurem osa Bassetki kujust on hävinud, säilinud on vaid jalad ja alumine osa kehast, kuid inskriptisoon on täitsa loetav.

${ }^{14}$ Selle teksti (Bassetki) eestikeelne tõlge on esmakordselt avaldatud P. Espaki ja V. Sazonovi artiklis "Idamaise despotismi lätted. Kuningavõim muistses Sumeris ja Akkadis" (Espak \& Sazonov 2005: 39); vt ka saksakeelset tõlget: Farber 1983: 67-72; Sazonov 2007a: 15; Sazonov 2008b: 201.

${ }^{15}$ Kuigi tegelikult oli esimene jumalikustatud valitseja Akkadi kuningas Narām-Su'en, kelle kohta vt Sazonov 2007a, Sazonov 2007c.

${ }^{16}$ Huvitaval kombel pole Sumeri kuningate nimekirjas mainitud ühtegi Lagaši valitsejat. Seda võiks seletada asjaoluga, et Ur III ajal oli levinud arusaam, et Lagaši valitsejad tegid kollaboratsionistlikku koostööd võõrvõimuga - vallutajate guutilastega ning selle tõttu otsustati karistada Lagaši Sumeri kuningate nimekirjast väljajätmisega.

${ }^{17}$ Read 95-98, 102-115 Sumeri kuningate nimekiri, on tõlgitud eesti keelde sumeri kirjanduse korpuse internetiväljaande järgi (ETCSL c 2.1.1; vt ka Sazonov 2007b: 2013-2014).

18 Vt Hammurapi Borsippa inskriptsiooni, read 14-15, kus Hammurapi kohta on kirjutatud Šamaši poolt tahetud ja Sippari inskriptsiooni (read 36-46) (Borger 1963: 1).

${ }^{19}$ Arinna päikesejumalanna oli seotud ka Neriki äikesejumala Tešubiga, kes oli ühtlasi hetiitide peajumal. Arinna jumalanna oli tuntud Wurusemu nime all. Wurusemu nime kohta vt lähemalt Maqueen 1959: 175-176.

\section{Kirjandus}

Aboud, Jehad 1994. Die Rolle des Königs und seiner Familie nach den Texten von Ugarit. Forschungen zur Anthropologie und Religionsgeschichte 27. Münster: Ugarit-Verlag.

Annus, Amar 2001. Paabeli Marduk ja Hammurapi, Tuna 3, lk 9-19.

MSA 2001 = Annus, Amar (tlk) \& Kolk, Kaspar \& Puhvel, Jaan \& Päll, Janika 2001. Muinasaja seadusekogumike antoloogia. Tallinn:Varrak.

Archi, Alfonso \& Klengel, Horst 1980. Ein hethitischer Text über die Reorganisation des Kultes. Altorientalische Forschungen 7, lk 143-157.

Beckman, Gary 2002. "My Sun-God" - Reflections of Mesopotamian Conceptions of Kingship among the Hittites. Panaino, Antonio \& Pettinato, Giovanni \& Basello, Gian Pietro \& Piras, Andrea (toim). Ideologies as Intercultural Phenomena. Proceedings of the third annual Symposium of the Assyrian and babylonian Intellectual Heritage Project, held in Chicago, USA, October 27-31, 2000. Melammu Symposia 3. Milan: Università di Bologna \& IsIao, lk 37-43 (http://www.aakkl.helsinki.fi/melammu/pdf/ beckman2002.pdf - 26. juuni 2009). 
Berlev 2003 = Берлев, Олег Д. 2003. Два царя - Два Солнца: к мировоззрению древних египтян. Quirke, Stephen (toim). Discovering Egypt from the Neva: The Egyptological Legacy of Oleg D. Berlev. Взгляд на Египет с берега Невы: Египтологическое наследие Олега Дмитриевича Берлева. Berlin: Achet Verlag, lk 1-18 (http:// www.egyptology.ru/berlev/2-2.pdf - 26. juuni 2009).

Bin-Nun, Shoshanna R. 1975. The Tawananna in the Hittite Kingdom. Texte der Hethiter 5. Heidelberg: Carl Winter Universitätsverlag.

Borger, Riekele 1963. Babylonisch-Assyrische Lesestücke II, Die Texte im Umschrift. Roma: Pontificium Institutum Biblicum.

Bossert, Helmuth Theodor 1957. Meine Sonne, Orientalia 26, lk 97-122.

Bryce, Trevor 2005. The Kingdom of The Hittites. Teine trükk. New York: Oxford University Press.

Buccellati, Giorgio \& Kelly-Buccellati, Marilyn 2002. Tar'am-Agade, Daughter of Naram-Sin, at Urkesh. Of Pots and Plans. Papers on the Archaeology and History of Mesopotamia and Syria presented to David Oates in Honour of his 75th Birthday. London: Nabu Publications, lk 11-31.

CAD 17 = Brinkman, John A. \& Civil, Miguel \& Gelb, Ignace J. \& Oppenheim, Leo A. \& Reiner, Erica (toim) 1989. The Assyrian Dictionary of The Oriental Institute of University of Chicago 17, Š, I osa. Chicago, Illinois: The Oriental Institute \& Glückstadt: J. J. Augustin Verlagsbuchhandlung.

Clauss, Manfred 2001. Das Alte Ägypten. Berlin: Fest.

Cornelius, Friedrich 1971. Das hethitische Königtum verglichen mit dem Königtum des sprachverwandten Völker. Thureau-Dangin, François (toim). Le Palais et la Royaute - 19e Rencontre Assyriologique Internationale. CRRAI 19, Paris: D. O. Edzard, lk 323326.

Di Vito Robert A. 1993. Studies in Third Millennium Sumerian and Akkadian Personal Names, The Designation and Conception of the Personal God. Studia Pohl: Series Maior, Dissertationes scientifiecae de rebus orientis antiqui 16. Roma: Editrice Pontificio Istitutio Biblico.

Djakonov 1959 = Дьяконов, Игорь М. 1959. Общественный и государственный строй древнего Двуречья: Шумер. Москва: Издательство восточной литературы.

Diakonov 1990 = Дьяконов, Игорь М. 1990. Люди города Ура. Москва: Наука.

Edzard, Dietz Otto 1989. Das "Wort im Ekur" oder Perepetie in "Fluch über Akkade". Behrens, Hermann \& Loding, Darlene \& Roth, Martha T. (toim). Dumu-E2-DUB-BA-A, Studies in Honor of Ake Sjöberg. Occasional Publications of the Samuel Noah Kramer Fund, 11, Philadelphia: The University Museum, lk 99-105.

Jemeljanov 2003 = Емельянов, Владимир В. Древний Шумер: очерки культуры. Санкт-Петербург: Азбука-классика, Петербургское Востоковедение.

Espak, Peeter \& Sazonov, Vladimir 2005. Idamaise despotismi lätted. Kuningavõim muistses Sumeris ja Akkadis. Horisont 5, lk 34-41. 
Espak, Peeter 2006. Ancient Near Eastern Gods Enki and Ea: Diachronical Analysis of Texts and Images from the Earliest Sources to the Neo-Sumerian Period. Magistritöö. Tartu: Tartu Ülikool.

ETCSL = Black, Jeremy \& Cunningham, Graham \& Ebeling, Jarle \& Flückiger-Hawker, Esther \& Robson, Eleanor \& Taylor, Jon \& Zólyomi, Gábor (toim). The Electronic Text Corpus of Sumerian Literature. Oxford: University of Oxford (http://etcsl.orinst.ox.ac.uk/ - 29. juuni 2009).

Farber, Walter 1983. Die Vergöttlichung Narāmsins, Orientalia NS 52, lk 67-72.

FAOS 7 = Gelb, Ignace J. \& Kienast, Burkhart 1990. Die altakkadischen Königsinschriften des Dritten Jahrtausends v.Chr. Freiburger Altorientalische Studien 7. Stuttgart: Franz Steiner Verlag.

Fauth, Wolfgang 1979. Sonnengottheit ( $\left.{ }^{d} \mathrm{UTU}\right)$ und "Königliche Sonne ( ${ }^{d} \mathrm{UTU}$-ši) bei den Hethitern. Berghof, K. \& Dietrich, Manfred \& Loretz, Oswald (toim). Festschrift für Claude F. A. Shaeffer zum 80. Geburtstag am 6. Märtz 1979, Ugarit-Forschungen. Internationales Jahrbuch für die Altertumskunde Syrien-Palästinas 11. Verlag Butzon \& Bercker Kevelaer, Neukirchener Verlag, Neukirchen Vluyn, lk 227-263.

Gelb, Ignace J. 1949. The date of the Cruciform Monument of Maništušu. Journal of Near Eastern Studies 8: 4, lk 346-348

Gelb, Ignace J. 1952. Sargonic Texts from the Diyala Region. Chicago: The University of Chicago Press.

Gonnet, Hatice 1987. Tabarna, Favori des Dieux? Lebrun, René (toim). Hethitica VIII, Acta Anatolica. E. Laroche oblata. Paris: Colloque anatolien, lk 177-185.

Gurney, Oliver R. 1984. The Hittite Title Tuhkanti. Anatolian Studies XXXIII, 1983, Special Number in honour of the seventy-fifth birthday of Dr. Richard Barnett, 23 January, lk 97-101.

Güterbock, Hans Gustav 1940. Siegel aus Boğazköy, Erster Teil: Die Königssiegel der Grabungen bis 1938. Archiv für Orientforschung, Beiheft 5, I. Berlin: E. F. Weinder.

Haas, Volkert 1994. Geschichte der hethitischen Religion. Handbuch der Orientalistik I. Der Nahe und Mittlere Osten 15. Leiden \& New York \& Köln: E.J.Brill.

Haas Volkert 2006. Die hethietische Literatur: Texte, Stilistik, Motive. Berlin \& NewYork: Walter de Gruyter.

IDM 1989 = Дьяконов, Игорь М. \& Неронова, Валентина Д. \& Свенцицкая, Ирина C. (toim). История Древнего Мира, ранняя древность. 3. tдiendatud trıkk. Москва: Главная редакция восточной литературы.

Klengel, Evelyn \& Klengel, Horst 1970. Die Hethiter und ihre Nachbarn: Eine Kulturgeschichte Kleinasiens von Catal Hüyük bis zu Alexander dem Großen. Leipzig: Koehler \& Amelang.

Kulmar, Tarmo 2007. Tõsilood muinasrahvastest. Tartu: Ilmamaa.

Maqueen, J.G. 1959. The Hattian Mythology and Hittite Monarchy. Anatolian Studies 9, lk 171-188.

Matthews, Donald \& Eidem, Jesper 1993. Tell Brak and Nagar. Iraq 55, lk 201-207. 
Maul, Stephan 1999. Der assyrische König. Hüter der Weltordnung. Watanabe, Kazuko (koost). Priests and Officials in the Ancient Near East. Papers an the Second Colloquium on the Ancient Near East - The City and its Life, held at the Middle Eastern Culture Center in Japan, March 22-24. 1996, Heidelberg: Carl Winter Verlag, lk 201-214

Meyer, Eduard 1928. Geschichte des Altertums II/1, Stuttgart: J.GF. Cotta'sche Buchhandlung Nachfolger.

Montet, Pierre 2000 = Монте, П. Повседневная жизнь египтян во временя великих фараонов. Москва: Молодая Гвардия, Палимпсест.

Moran, William L. 1992. The Amarna Letters. Baltimore \& London: The Johns Hopkins University Press.

Moret, Alexandre 2007 = Морэ, Александр. Нил и египетская цивилизация. Загадки древнего Египта. Любовская, T. (tlk). Москва: Центрполиграф.

Otten, Heinrich 1981. Die Apologie Hattusilis III. Das Bild der Überlieferung. Studien zu Bogazköy-Texten 24. Wiesbaden: Otto Harrasowitz.

Puhvel, Jaan 2002. Epilecta Indoeropaea, Opuscula Selecta Annis 1978-2001 Excusa Imprimis ad Res Anatolicas Attinentia. Innsbruck: Institut für Sprachen und Literaturen.

RIMA 1 = Grayson, Albert Kirk 1987. Assyrian Rulers of the Third and Second Millennia $B C$ (to 1115 BC). The Royal Inscriptions of Mesopotamia, Assyrian Periods 1. Toronto \& Bufallo \& London: University of Toronto Press [kordustrükk 2002].

Roth, Martha Tobi 1997. Law collections from Mesopotamia and Asia. Michalowski, Piotr (toim). Atlanta: Scholars Press.

Sazonov, Vladimir \& Veede, Raul (tlk) 2005. Gilgameš ja Akka. Annus, Amar (koost). Muinasaja kirjanduse antoloogia. Tallinn: Varrak, lk 49-53.

Sazonov, Vladimir 2007a. Akkadi kuningate jumalikustamine. Tuna 2, lk 11-23.

Sazonov, Vladimir 2007b. Sumeri varajane kuningavõim 28.-24. saj eKr. Akadeemia 9, lk 2001-2031.

Sazonov, Vladimir 2007c. Vergöttlichung der Könige von Akkade. Kämmerer, Thomas Richard (toim). Studien zu Ritual und Sozialgeschichte im Alten Orient. Studies on Ritual and Society in the Ancient Near East. Beihefte zur Zeitshrift für alttestamentliche Wissenschaft 374. Berlin \& New York: Walter de Gruyter \& Co, lk 325-341 (http:// books.google.ee/books?id=gGDiUTpFRoMC\&hl=en\&source=gbs_navlinks_s - 27. juuni 2009).

Sazonov, Vladimir 2008a. Kuninglik propaganda Kesk-Assüüria suurriigis 1365-1208 eKr valitsejate tiitlite näol. Tuna 4, lk 5-15.

Sazonov, Vladimir 2008b. Akkadi kuningavõim kui arhetüüp. Ajalooline Ajakiri 3, lk $195-214$

Sazonov, Vladimir 2009. Hetiidi kuningate titulatuuri arengujoontest 17.-13. saj eKr. Kulmar, Tarmo \& Ude, Indrek (toim). Eesti Akadeemilise Orientaalseltsi Aastaraamat 2008. Tartu, lk 30-51.

Stadnikov, Sergei 1998. Vana Egiptuse Kultuurilugu: valitud artikleid, tõlkeid ja esseid, Tallinn: Kodutrükk. 
Stadnikov 2007 = Стадников, Сергей. Окружённый солнцем владыка. Универсализм как феномен в идеологии египетских царей. Вышгород 5, lk 104-127 (http:// www.vptv.planet.ee/vyshgorod/5_2007.pdf - 27. juuni 2009).

Weidner, Ernst 1970. Die Inschriften Tukulti-Ninurtas I. und seiner Nachfolger. Archiv für Orientforschung 12. Osnabrück: Biblio Verlag.

Westenholz, Joan Goodnick 1997. Legends of the Kings of Akkade. The Texts, Mesopotamian Civilizations 7. Winona Lake, Indiana: Eisenbrauns (http://books.google.ee/ books?id=izhhWQEJkrQC\&hl=en\&source=gbs_navlinks_s - 27. juuni 2009).

\section{Summary}

\section{On the Emergence and Development of the Concept of Sun King in Anatolia in the 2nd Millennium BC}

\section{Vladimir Sazonov}

Key words: Anatolia, Assyrians, divination of ruler, Egypt, Hittites, ideology, Mesopotamy, royal epithet, sun god

The concept of sun king was widely spread in ancient cultures, for example in Peru (among the Incas), India, and the Ancient Middle East already in the 2nd and 3rd millennium BC. In Ancient Egypt the perception of Pharaoh as the son of Ra and the sun king formed in the Old Kingdom by the middle of the 3rd millennium BC. The king was identified with the sun already by Hittites, Babylonians, and Assyrians in the 2nd millennium BC. Among the Hittites, 'My Sun', which could be interpreted also as 'Majesty', became the most popular royal title. The first Assyrian ruler to adopt the epithet 'the Sun God of All People' was the despotic Tukulti-Ninurta I (1244-1208). Until now, some scholars have argued that the concept of sun kind emerged in Mesopotamia and Anatolia under the influence of Egypt. This argument, however, has little ground because it is not likely, at least there is no record of it, that Egypt had contacts with Mesopotamia and Anatolia prior to the 3rd millennium BC, and by the 2nd millennium the contacts had been established but the influence of Egypt on Anatolia was rather limited. At the same time, the influence of Mesopotamia and the local Hattians, who had occupied Anatolia before the coming of Hittites, on the Hittite ideology was remarkable. Several concepts connected to Hittite royalty have been borrowed from Mesopotamia, and from Hattians. There is circumstantial evidence that the concept of sun king may have emerged at the end of the 3rd millennium BC in Sumer and Akkad, and from there spread to Anatolia. It cannot be ruled out, though, that the phenomenon may have emerged spontaneously and developed independently without major external influences. 